\title{
Commentary: The perils of the pump
}

\author{
Samuel Jacob, MD, and Kevin P. Landolfo, MD, MSc
}

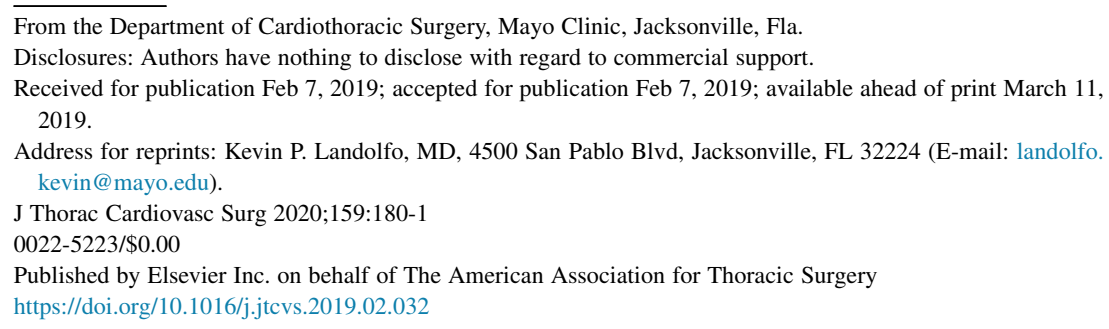

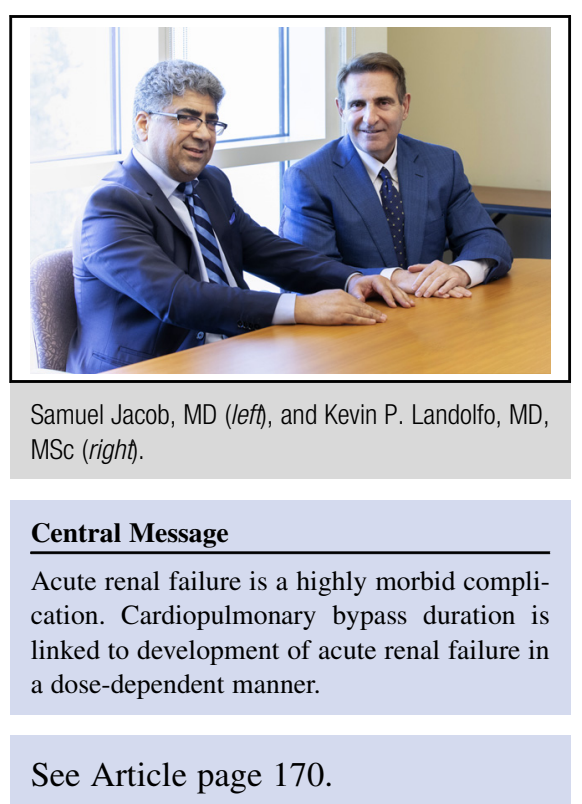

with impaired preoperative renal function (estimated glomerular filtration rate $<30 \mathrm{~mL} / \mathrm{min} / 1.73 \mathrm{~m}^{2}$ ), however, demonstrated a significant increase in the probability of ARF with CPB time $(6 \%$ per 1 hour of CPB; $25 \%$ for 5 hours of $\mathrm{CPB}$ ).

This study confirms the negative effect of ARF on patient outcomes in the current era of cardiac surgery. The mortality and morbidity observed in patients with postoperative ARF were high, consistent with previous reports in the literature. Importantly, this study demonstrated a unique dosedependent effect of CPB time (analyzed as a continuous variable) on ARF that was seen particularly in patients with impaired preoperative renal function. Axtell and colleagues ${ }^{1}$ suggest that preoperative consideration should be given to the risk of CPB time when lengthy, complex procedures are planned, particularly in patients with impaired renal function. Techniques to limit CPB time now possible in the current era, including hybrid endovascular and transcatheter procedures, should be considered. Concomitant procedures and the necessity of complete surgical repair should be measured against an observed 50\% mortality demonstrated in patients with ARF. Many surgeons consider the development of CPB to be a "great equalizer and the pump a friend to the cardiac surgeon." Although this is true to a degree, this study of Axtell and colleagues ${ }^{1}$ highlights the fact that limiting CPB times where possible and efficient CPB are important to limiting the "perils of the pump." 


\section{References}

1. Axtell AL, Fiedler AG, Melnitchouk M, D’Alessandro DA, Villavicencio MA, Jassar AS, et al. Correlation of cardiopulmonary bypass duration with acute renal failure after cardiac surgery. J Thorac Cardiovasc Surg. 2020;159:170-8.e2.

2. Mangano CT, Diamondstone LS, Ramsay JG, Aggarwal A, Herskowitz A, Mangano DT. Renal dysfunction following myocardial revascularization: risk factors, adverse outcomes and hospital resource utilization. The multicenter study of perioperative ischemia research group. Ann Intern Med. 1998;128: 194-203.

3. Ostermann ME, Taube D, Morgan CJ, Evans TW. Acute renal failure following cardiopulmonary bypass: a changing picture. Intensive Care Med. 2000;26:565-71.

4. Swaminathan M, Shaw AD, Phillips-Bute BG, McGugan-Clark PL, Archer LE Talbert S, et al. Trends in acute renal failure associated with coronary artery bypass graft surgery in the United States. Crit Care Med. 2007;35:2286-91. 